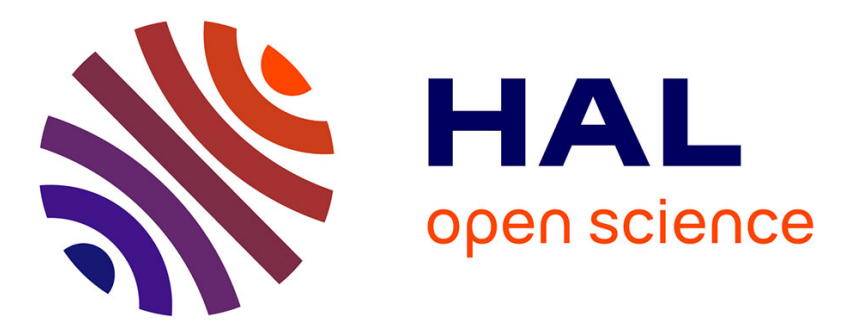

\title{
Optic neuropathy linked to ACAD9 pathogenic variants: a potentially riboflavin-responsive disorder?
}

Naig Gueguen, Julie Piarroux, Emmanuelle Sarzi, Mehdi Benkirane, Gael

Manes, Cécile Delettre, Pascal Amedro, Nicolas Leboucq, Michel Koenig, Pierre Meyer, et al.

\section{To cite this version:}

Naig Gueguen, Julie Piarroux, Emmanuelle Sarzi, Mehdi Benkirane, Gael Manes, et al.. Optic neuropathy linked to ACAD9 pathogenic variants: a potentially riboflavin-responsive disorder?. Mitochondrion, 2021, pp.169-174. 10.1016/j.mito.2021.05.002 . hal-03234769

\section{HAL Id: hal-03234769 \\ https://hal.science/hal-03234769}

Submitted on 14 Jun 2021

HAL is a multi-disciplinary open access archive for the deposit and dissemination of scientific research documents, whether they are published or not. The documents may come from teaching and research institutions in France or abroad, or from public or private research centers.
L'archive ouverte pluridisciplinaire HAL, est destinée au dépôt et à la diffusion de documents scientifiques de niveau recherche, publiés ou non, émanant des établissements d'enseignement et de recherche français ou étrangers, des laboratoires publics ou privés. 


\title{
Optic neuropathy linked to ACAD9 pathogenic variants: A potentially riboflavin-responsive disorder?
}

\author{
Naig Gueguen ${ }^{\text {a,b,1, }}$, Julie Piarroux ${ }^{\text {c, } 1}$, Emmanuelle Sarzi ${ }^{\mathrm{d}}$, Mehdi Benkirane ${ }^{\mathrm{e}, \mathrm{f}}$, Gael Manes ${ }^{\mathrm{g}}$, \\ Cécile Delettre $^{g}$, Pascal Amedro ${ }^{\mathrm{e}, \mathrm{h}}$, Nicolas Leboucq ${ }^{\mathrm{i}}$, Michel Koenig ${ }^{\mathrm{e}, \mathrm{f}}$, Pierre Meyer ${ }^{\mathrm{c}, \mathrm{e}}$, \\ Isabelle Meunier ${ }^{j}$, Pascal Reynier ${ }^{a, b}$, Guy Lenaers ${ }^{b, 1}$, Agathe Roubertie ${ }^{c, g, j, 1, *}$ \\ ${ }^{\text {a }}$ Department of Biochemistry and Molecular Biology, CHU Angers, 49933 Angers, France \\ b University of Angers, Unité Mixte de Recherche (UMR) MITOVASC, Centre National de la Recherche Scientifique (CNRS) 6015, Institut National de la Santé et de la \\ Recherche Médicale (INSERM) U1083, 49933 Angers, France \\ ${ }^{\mathrm{c}}$ CHU Montpellier, Département de Neuropédiatrie, Montpellier, France \\ d NeuroMyoGene Institute-UCBL/CNRS UMR5310/INSERM U1217-Lyon, France \\ ${ }^{\mathrm{e}}$ PhyMedExp, CNRS, INSERM, University of Montpellier, Montpellier, France \\ ${ }^{\mathrm{f}}$ Laboratoire de Génétique Moléculaire, Institut Universitaire de Recherche Clinique, CHU de Montpellier, France \\ ${ }^{g}$ INM, University Montpellier, INSERM, Montpellier, France \\ ${ }^{\mathrm{h}}$ Pediatric and Adult Congenital Cardiology Department, M3C Rare Cardiac Disease Reference Center, CHU Montpellier, France \\ ${ }^{i}$ Département de Neuroradiologie, CHU Montpellier, Montpellier, France \\ ${ }^{\mathrm{j}}$ National Center in Rare Diseases, Genetics of Sensory Diseases, University Hospital, Montpellier, France
}

\section{A R T I C L E I N F O}

Keywords:

Optic neuropathy

ACAD9

Complex I

Riboflavin

\begin{abstract}
A B S T R A C T
Mitochondrial complex I (CI) deficiencies (OMIM 252010) are the commonest inherited mitochondrial disorders in children. Acyl-CoA dehydrogenase 9 (ACAD9) is a flavoenzyme involved chiefly in CI assembly and possibly in fatty acid oxidation. Biallelic pathogenic variants result in CI dysfunction, with a phenotype ranging from early onset and sometimes fatal mitochondrial encephalopathy with lactic acidosis to late-onset exercise intolerance. Cardiomyopathy is often associated. We report a patient with childhood-onset optic and peripheral neuropathy without cardiac involvement, related to CI deficiency. Genetic analysis revealed compound heterozygous pathogenic variants in $A C A D 9$, expanding the clinical spectrum associated to ACAD9 mutations. Importantly, riboflavin treatment $(15 \mathrm{mg} / \mathrm{kg} /$ day) improved long-distance visual acuity and demonstrated significant rescue of $\mathrm{CI}$ activity in vitro.
\end{abstract}

\section{Introduction}

Inherited Optic Neuropathies (ION) are a heterogeneous group of diseases, characterized by the loss of retinal ganglion cells, leading to bilateral loss of central vision. ION share common physiopathological mechanisms related to mitochondrial dysfunction affecting energy metabolism or network dynamics (Maresca et al., 2012).

Mitochondrial complex I (CI) or NADH:ubiquinone reductase (EC 7.1.1.2) is one of the four complexes forming the electron transport chain (ETC). CI deficiencies (OMIM 252010) represent up to one third of inherited mitochondrial diseases, and are caused by nuclear or mitochondrial genome pathogenic variants. Symptoms vary widely in nature and severity, ranging from isolated sensorial diseases, as in Leber hereditary optic neuropathy or Dominant Optic Atrophy, to early onset multisystemic neurodegenerative phenotypes with poor outcome (Fiedorczuk and Sazanov, 2018; Koene et al., 2012).

Here, we report the case of a patient with childhood onset optic neuropathy associated with peripheral neuropathy, but without any cardiomyopathy, related to compound heterozygous pathogenic variants in the acyl-CoA dehydrogenase 9 (ACAD9) gene. Importantly, riboflavin treatment improved long distance visual acuity and demonstrated significant rescue of CI activity in vitro.

\footnotetext{
* Corresponding authors: Département de Neuropédiatrie, CHU Gui de Chauliac, 80 Avenue Fliche, 34295 Montpellier, France. E-mail address: a-roubertie@chu-montpellier.fr (A. Roubertie).

1 These authors contributed equally to the manuscript.
} 


\section{Material and methods}

Informed consents were obtained from the parents to perform genetic, biochemical and molecular analyses and to publish all data. The study was carried out in accordance with the Declaration of Helsinki and was approved by Montpellier University Hospital Institutional Review Board.
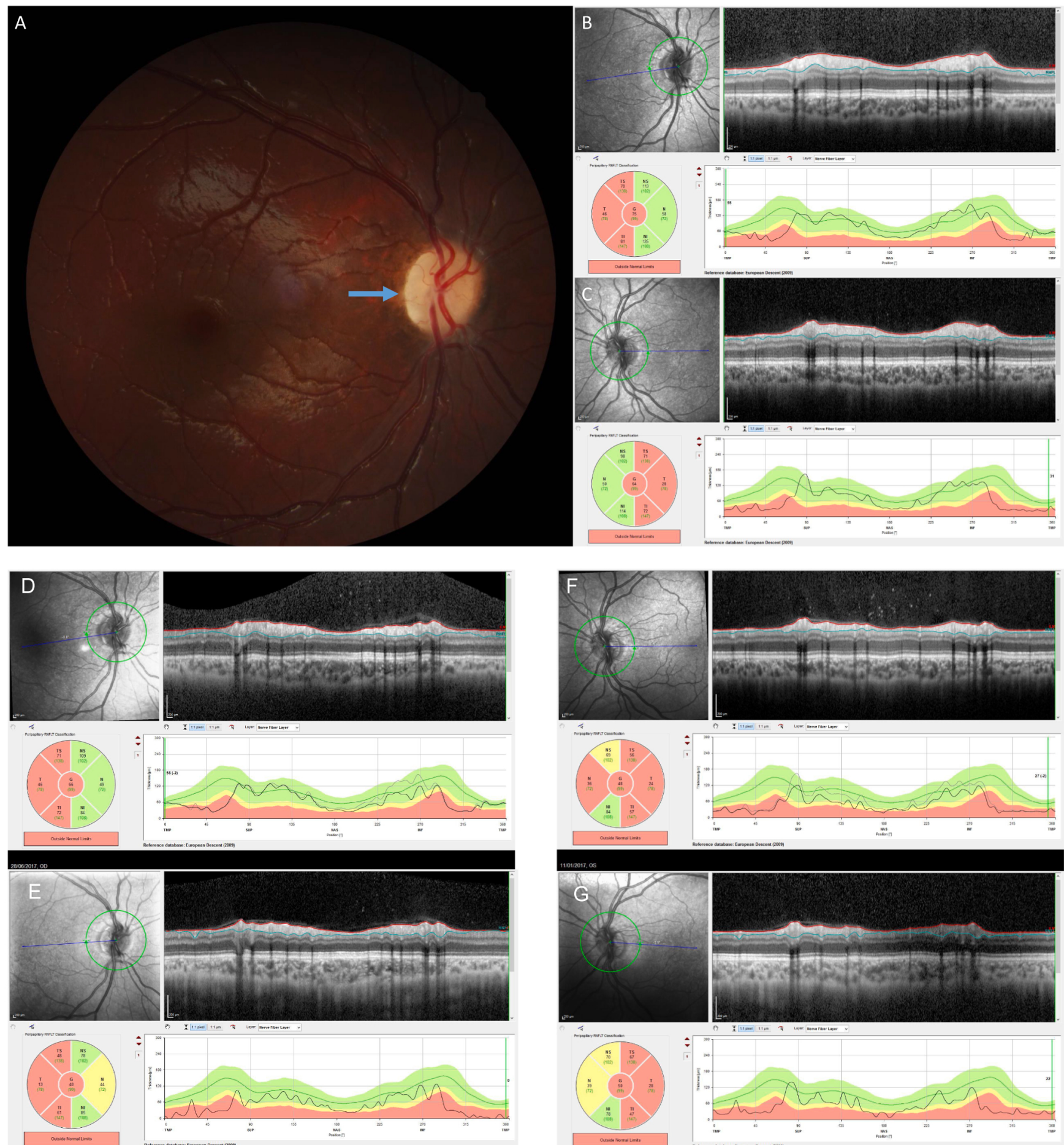

Figure 1. Ophtalmological assessment of the patient.
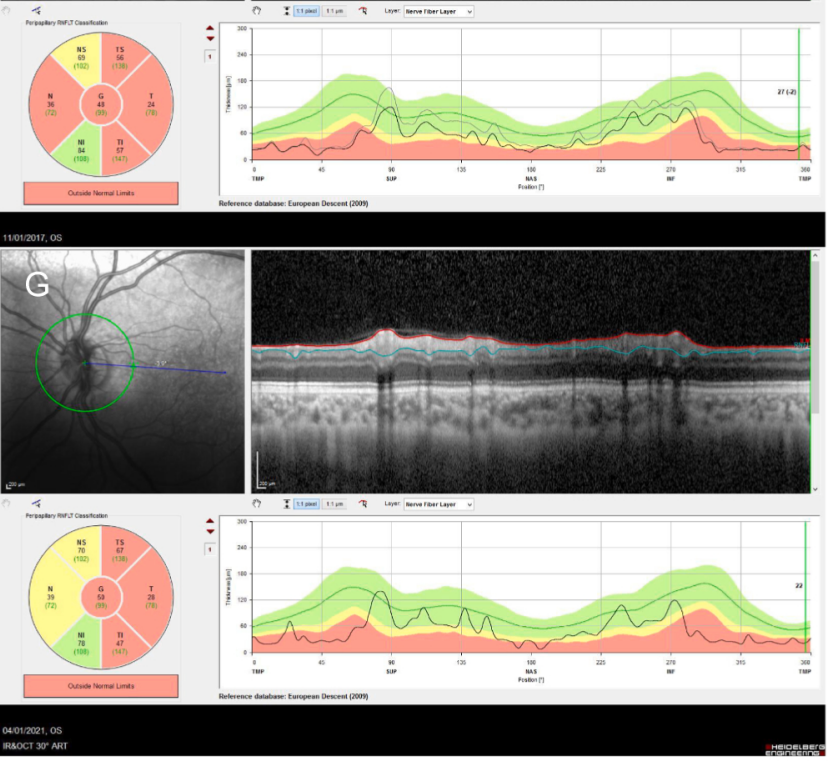

Fig. 1. Ophtalmological assessment of the patient. A. Initial examination of the patient at the age of 7 years. Visual acuity was $20 / 125 \mathrm{P} 5 \mathrm{in}$ the right eye and $20 / 200$ P5 left eye. A fundus picture of the right eye. Note the temporal pallor (blue arrow). B-G: Retinal Nerve Fiber Layer (RNFL) analysis. Significant thinning of the temporo-macular bundle in both eyes. B: initial RNFL, right eye; temporal thickness $46 \mu \mathrm{m}$, visual acuity 20/125 P5. C: initial RNFL, left eye; temporal thickness 28 $\mu \mathrm{m}$, visual acuity 20/200. P5. D: RNFL before treatment, right eye, temporal thickness $46 \mu \mathrm{m}$, visual acuity 20/400 P6. E: last follow-up, right eye; temporal thickness $13 \mu \mathrm{m}$, final visual acuity 20/100 P10. F: RNFL before treatment, left eye; temporal thickness $27 \mu \mathrm{m}$, visual acuity 20/400 P6. G: left eye, last follow-up; temporal thickness $28 \mu \mathrm{m}$, final visual acuity 20/100 P10. 


\section{Results}

\subsection{Case report}

The patient was the second child of healthy and non-consanguineous parents. Family history, pregnancy and perinatal period were uneventful. Psychomotor development was normal (walk unaided at 12 months of age, first sentences at 3 years of age). He was reported since the age of 3 as clumsy, with coordination difficulties, awkward gait and walking fatigability. The patient was referred at 6.8 years of age for progressive visual disability. Visual acuity was 20/125 P5 in the right eye and 20/ 200 P5 in the left eye, with dark colors dyschromatopsia. Fundus examination revealed bilateral optic disc pallor with temporal predominance (Fig. 1A) and spectral-domain optical coherence tomography (SDOCT) disclosed a marked decrease in the thickness of the retinal nerve fiber layer on the temporal area (Fig. 1B, D). Neurological examination showed steppage gait, distal muscular weakness, discrete calf atrophy and abolished deep tendon reflexes on the four limbs. General examination was normal, height and weight parameters were below 1.5 SD, and cognitive function was normal.

Electophysiological recording disclosed the absence of sensory potentials, in agreement with sensory neuropathy of the four limbs. Auditory evoked potentials and audiometry, transthoracic echocardiography and electrocardiogram (ECG) were normal.

Laboratory parameters disclosed slightly elevated levels of lactate (3.1 mmol/1, normal range 0.5-2.2) and alanine (554 micromol/1, normal range 168-510) with normal bicarbonate levels at 6.8 years of age; creatine phosphokinase, ammonia, acyl carnitine profile, renal and hepatic functions were normal. Cerebro-medullar magnetic resonance imaging (MRI) did not reveal any structural abnormality, while cerebral spectroscopy disclosed an elevated lactate peak.

Orthoptic and physical therapy was initiated, and the patient benefited from school facilities.

At 7.5 and 8.5 years of age, visual acuity had decreased to $20 / 400$ P10 in the right eye and 20/400 P14 in the left eye; bilateral thinning of the retinal fiber layer was more obvious on the OCT; neurological examination remained unchanged. Ophthalmological worsening was confirmed by brain MRI that showed discrete optic tract atrophy (data not shown). Biological analysis of lactate and amino-acids were normal.

At 8.5 years of years, given the visual acuity worsening and the mitochondrial dysfunction together with the molecular diagnosis (see below), riboflavin $15 \mathrm{mg} / \mathrm{kg} /$ day and ibedenone $22 \mathrm{mg} / \mathrm{kg} /$ day supplementations were initiated. The treatment was well tolerated after reducing idebenone supplementation to $15 \mathrm{mg} / \mathrm{kg}$ /day, due to digestive disturbances. Idebenone was discontinued after one year, whereas riboflavin was maintained.

A couple of months after treatment initiation, the parents noticed a better appetite and improvement of lower limb fatigue and visual function. At 9.5 years, visual acuity was 20/100 P10 in both eyes. At last follow-up at $\mathbf{1 1}$ years of age, the patient was stable in terms of visual acuity except for near vision difficulties; thickness of the retinal nerve fiber layer remained unchanged on the left eye (Fig. 1D-G). Clinical examination and growth parameters were stable. The patient was independent for all daily living activities and was able to walk a distance of $3 \mathrm{~km}$. Academic achievements were normal. The patient underwent a complete cardiac assessment, including echocardiography, cardiac MRI, 24-hour ECG monitoring and cardio-pulmonary exercise test, which was normal. Brain MRI was unchanged.

\subsection{Genetics}

Gene panel sequencing identified that the patient harbored two ACAD9 variants: c.358delT p.(Phe120Serfs*9) inherited from his mother, resulting in a frameshift and occurrence of a premature stop codon, and c.1562A > G p.(Lys521Arg) inherited from his father, substituting an amino-acid that is invariant among all metazoans. Both variants were present in GnomAD with a frequency of $10^{-4}$ and $8 \times$ $10^{-6}$, respectively. According to Varsome analysis, the c.358delT variant was classified pathogenic (PVS1, PM2, PP3 and PP5), and the c.1562A > G variant likely pathogenic (PP2, PP3 and PM2) according to the ACMG classification. No mutation was identified in genes involved in inherited optic atrophies or in riboflavin transport or metabolism (Mosegaard et al., 2020).

3.3 Respiratory chain complex maximal activities and maximal phosphorylating respirations (Fig. 2A, B): Complex 1 deficiency

The specific CI activity (NUR activity normalized to CS, NUR/CS, Fig. 2A) was decreased in the patient and in the positive control ( $\mathrm{Ctr}+$ ) ACAD9-mutated cell lines $(-51 \%,>3 \mathrm{SD} ;-30 \%,>2$ SD for patient and $\mathrm{Ctr}+$ cells, respectively), while activities of the complexes II, III, IV and the F1-ATPase were unchanged, demonstrating an isolated CI deficiency (Fig. 2A). By contrast, the maximal CI-linked respirations (Fig. 2B, State $3 \mathrm{MP}$ and MPG) were mostly preserved (-30\% and $-16 \%$ in both patient and $\mathrm{Ctr}+$ cells, respectively $<2 \mathrm{SD}$ ).

3.4 Impact of the ACAD9 variants on CI assembly (blue native PAGE, Fig. 2C,D)

CI holoenzyme level was slightly decreased in both ACAD 9 mutated cells, compared to controls ( $66 \pm 18 \%$ and $72 \pm 20 \%$ in patient and Ctr + cells, respectively, Fig. 2C). To further analyze the blockade step in CI assembly, CI intermediates were revealed with assembly factors targeted antibodies (Fig. 2D). The $\sim 400 \mathrm{kDa}$ Pp-b intermediate assembly is assisted by the MCIA complex, which comprises ACAD9, (Fig. 2D, middle panel, lanes 1-3 and 5, marked with *) (Formosa et al., 2020). This intermediate assembly was present in control cells. However, in ACAD9 mutated cells (patient and $\mathrm{Ctr}+$ cells), the Pp-b intermediate could not be detected (Fig. 2D, middle panel), resulting in accumulation of the matrix intermediates $\mathrm{Q}$ and mostly Q/Pp-a (Fig. 2D, upper panel). Neither $\mathrm{Q}$ nor Pp-a intermediates require ACAD9 for their assembly. Inversely, in cells mutated in the CI NDUFS7 subunit, located in the $Q$ module, $\mathrm{Q}$ and $\mathrm{Q} / \mathrm{Pp}$-a matrix intermediates were lacking (Fig. 2D, upper panel) and a consistent accumulation of the membrane Pp-b intermediates was evidenced. These results indicate a major CI assembly defect linked to a specific impairment of assembly and/or stabilization of the ACAD9-containing submodule.

\subsection{Riboflavin treatment enhanced CI activity}

In the patient cells, $48 \mathrm{~h}$ riboflavin treatment dose-dependently increased CI activity, as measured by NUR activity (Fig. 2E) with a significant effect at $10 \mu \mathrm{M}(+81 \%, \mathrm{p}=0.049)$. This result is reinforced by CI IGA analysis (Fig. 2F), indicating an enhanced NADH-NTB reduction in patient cells treated with riboflavin. While riboflavin treatment stimulated CI activity, it did not alleviate the CI assembly defect: neither the CI holoenzyme level (Fig. 2G), nor the Pp-b assembly intermediate (Fig. $2 \mathrm{H}$ ) was increased, while the $\mathrm{Q} / \mathrm{Pp}$-a submodule showed marked accumulation.

\section{Discussion}

We report the case of a patient with normal cognitive function who developed childhood-onset rapidly progressive optic neuropathy associated to sensory neuropathy, lactic acidosis and lactate peak on brain spectroscopy. This phenotype suggested the diagnosis of a defect of energy metabolism and gene panel sequencing identified two ACADS variants.

Classically, the clinical presentation of ACAD9 deficiency (OMIM 611126) is mainly represented by cardiomyopathy. Other features include lactic acidosis, myopathy and developmental delay (Dewulf et al., 2016; Lagoutte-Renosi et al., 2015; Repp et al., 2018). Age of onset 
A

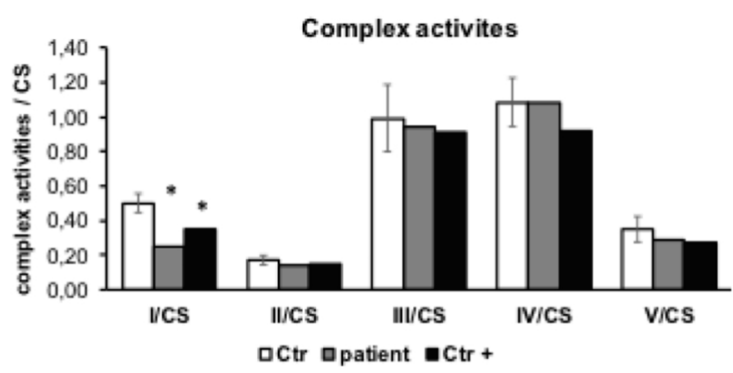

C

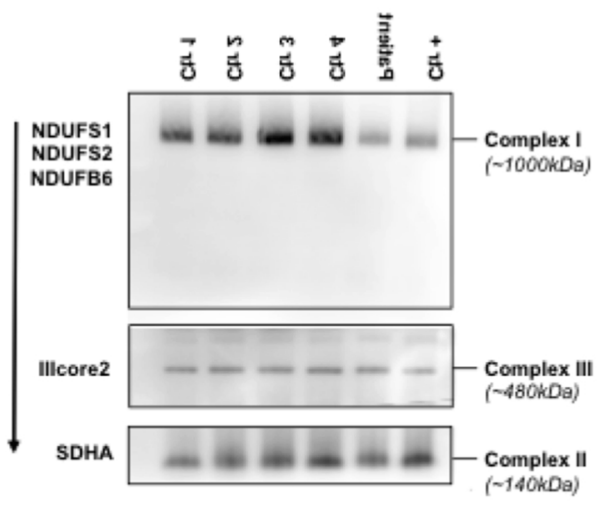

B

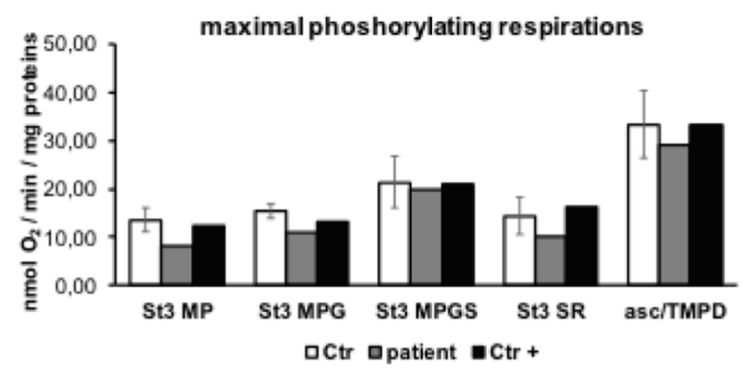

D

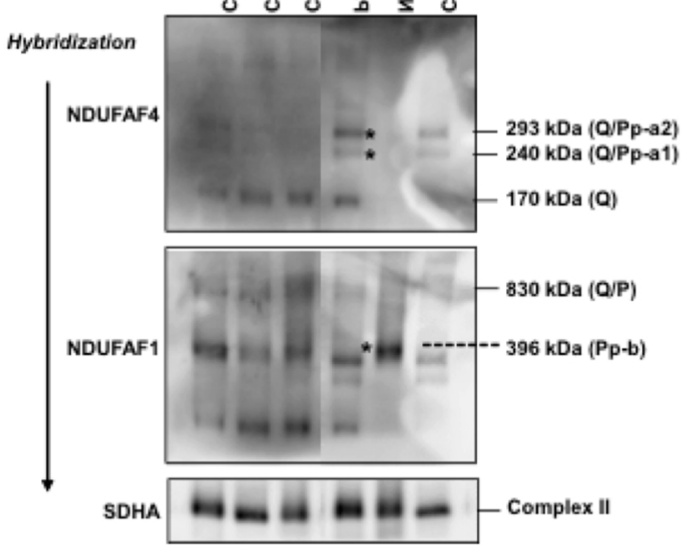

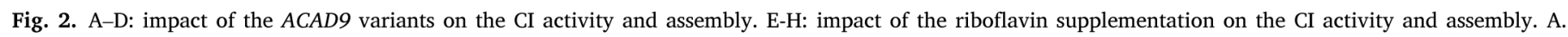

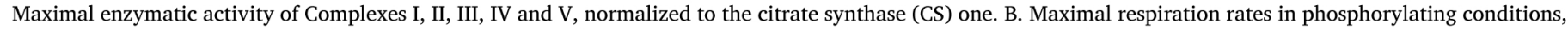

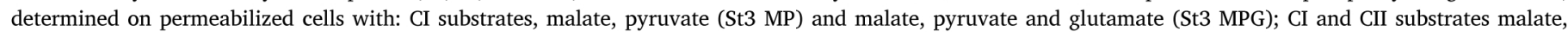

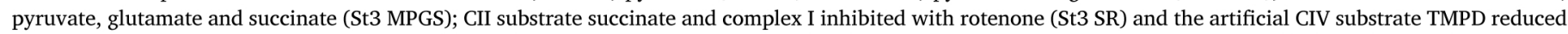

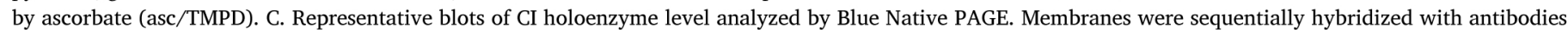

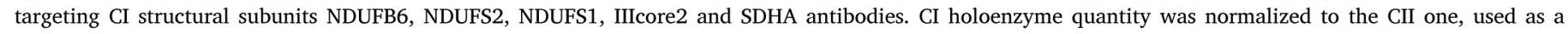

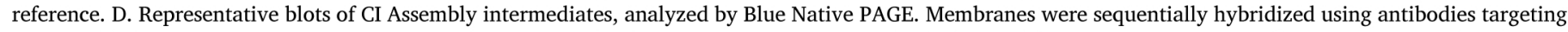

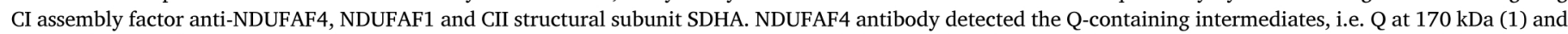

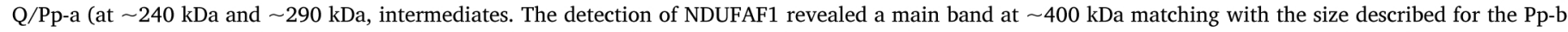

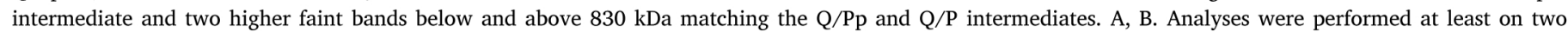

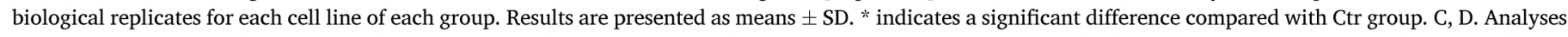

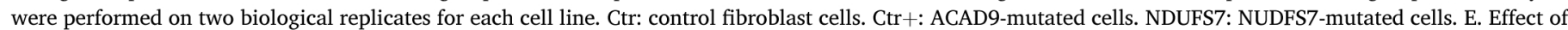

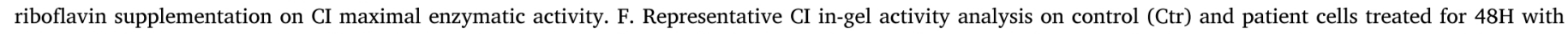

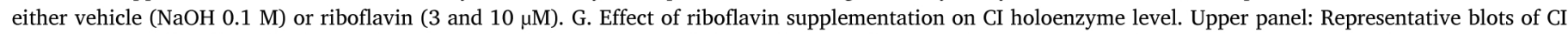

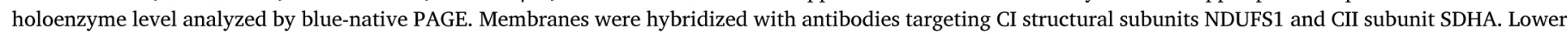

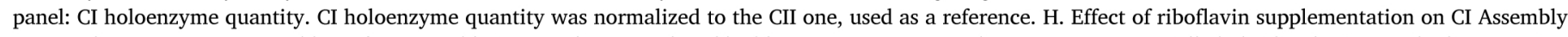

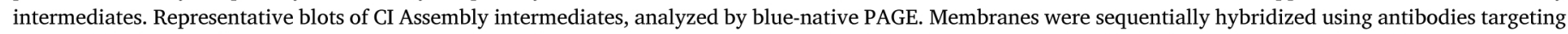

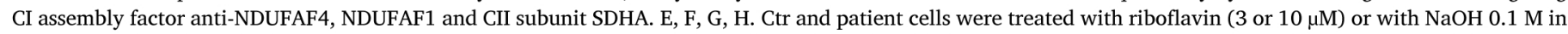

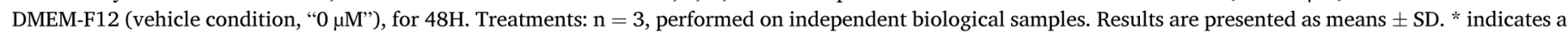

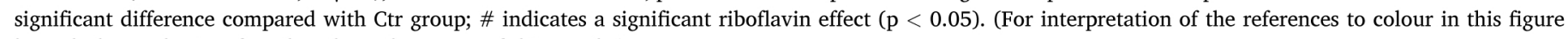
legend, the reader is referred to the web version of this article.)

and level of severity may vary, but usually early-onset is associated with poor survival. Severe intellectual disability is not common, and most patients who survive beyond the first 2 years are independent in daily living activities (Repp et al., 2018); mild phenotypes limited to myopathic features have been described (Repp et al., 2018; Schrank et al., 2017). Optic atrophy was reported in one patient with early-onset cardiomyopathy (Collet et al., 2015). Although we cannot exclude that optic nerve involvement was underestimated in previously published clinical cases, as funduscopic examination was not performed, the phenotype of our patient is singular and enlarges the phenotypic spectrum associated to $A C A D 9$ pathogenic variants.

Acyl-CoA dehydrogenase 9 is a mitochondrial flavoenzyme with structural similarities to very-long-chain acyl-CoA dehydrogenase, both enzymes catalyzing the initial step of the fatty acid oxidation. ACAD9 is also crucial for oxidative phosphorylation (Nouws et al., 2010). Indeed, it plays a central role among the core subunits that compose the mitochondrial CI assembly (MCIA) complex, involved in assembly of membrane intermediate Pp-b (Formosa et al., 2020; Nouws et al., 2010, 2013), and ACAD9 pathogenic variants leads to decreased CI assembly and activity (Haack et al., 2010).

The patient described here harbors compound heterozygous ACAD 9 variants, one pathogenic resulting in a stop codon already reported (Repp et al., 2018), the other predicted to be likely pathogenic. Biochemical and cell biology studies demonstrated reduced quantity of 
$\mathrm{E}$
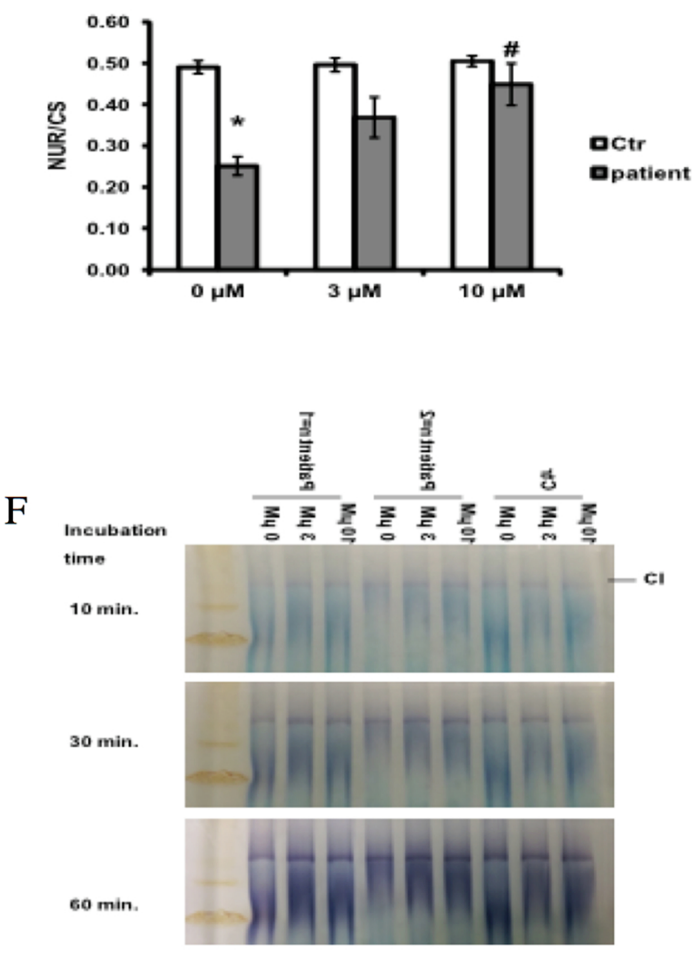
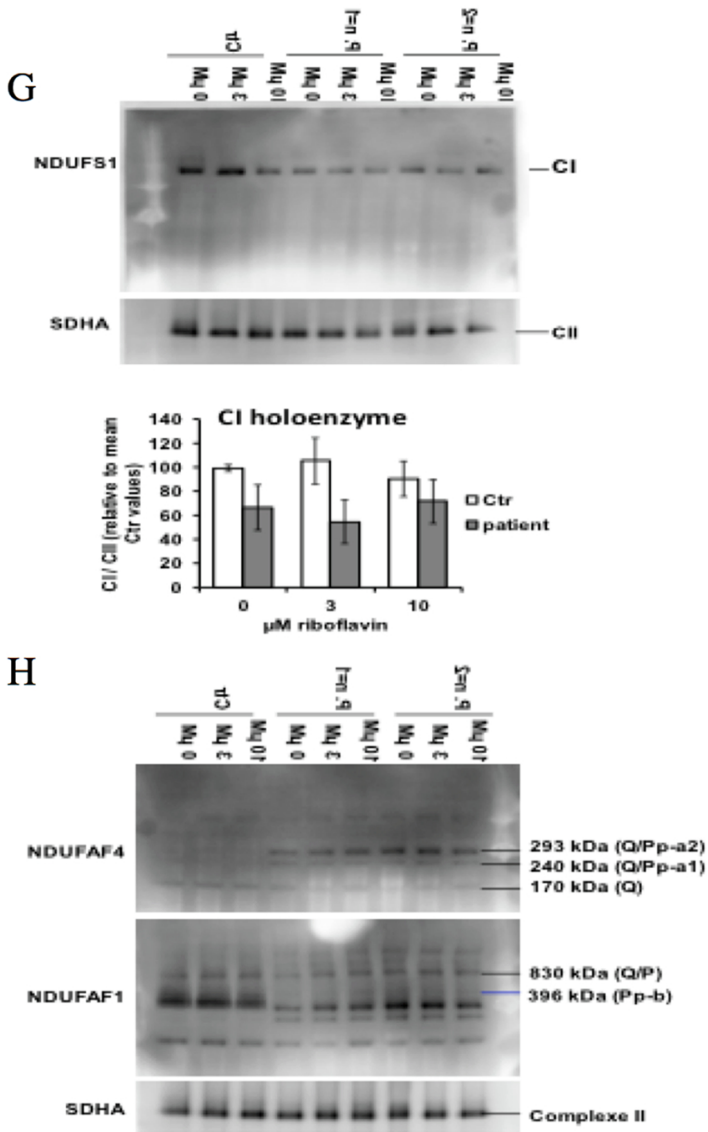

Fig. 2. (continued).

the CI Pp-b intermediate and disruption of CI assembly leading to decreased CI activity in the patient's fibroblasts, as well as in cells from a control $A C A D 9$ mutated patient. This result highlights the pathogenic effects of the patient's varaints and their functional significance, comparable to published cases (Nouws et al., 2010; Repp et al., 2018).

A major finding of this case is the improvement of the long distance visual acuity by riboflavin and idebenone treatment, even after eliminating idebenone supplementation due to secondary deleterious effects. Supporting this observation, we found that riboflavin supplementation improved CI activity in fibroblasts from our patient. Clinical benefit and improvement of CI activity by riboflavin supplementation have already been previously reported in most ACAD9 presentations (Gerards et al., 2010; Haack et al., 2010; Kadoya et al., 2019; Repp et al., 2018). Riboflavin is the vitamin precursor of FAD moiety, a cofactor of ACAD9. It has been hypothesized that riboflavin might increase ACAD9 activity and/or stability, resulting in improvement of CI assembly (Gerards et al., 2010). However, recent studies showed that bound-FAD cofactor is essential for ACAD9 acyl-CoA dehydrogenase activity, but is released through deflavination, when ACAD9 switches to its CI assembly function (Giachin et al., 2021). Accordingly, we found that riboflavin supplementation did not restore CI assembly in the fibroblasts from the patient described here, although CI activity was increased. Therefore, effects of riboflavin supplementation on CI activity might involve a more subtle cellular process unrelated to $\mathrm{CI}$ assembly, which could be linked to ACAD9 fatty acid oxidation activity (Schiff et al., 2015).

\section{Conclusion}

Therapeutic options for inherited optic neuropathies remain limited, although gene therapy appears to represent a promising approach (Gilhooley et al., 2021). Here, we enlarged the phenotypic spectrum associated to ACAD9 pathogenic variants, by describing a new form of syndromic optic neuropathy related to CI deficiency, which hopefully was responsive to riboflavin supplementation. We propose to screen $A C A D 9$ gene in patients with optic neuropathy, especially when associated to sensory peripheral neuropathy, and propose to consider riboflavin administration.

\section{Funding}

This work was partially funded by Santhera Pharmaceuticals.

\section{Declaration of Competing Interest}

The authors declare that they have no known competing financial interests or personal relationships that could have appeared to influence the work reported in this paper.

\section{Acknowledgements}

We acknowledge the patient and his family for participating in the study. We thank Dr Lagavulin for his helpful discussions.

\section{References}

M. Collet Z. Assouline D. Bonnet M.E.N. Rio F. Iserin D. Sidi A. Goldenberg C. Lardennois M.D. Metodiev B. Haberberger T. Haack A. Munnich H. Prokisch tig, A.E.S.R.O., 
High incidence and variable clinical outcome of cardiac hypertrophy due to ACAD9 mutations in childhood Eur. J. Hum. Genet. 1-5 2015 10.1038/ejhg.2015.264.

Dewulf, J.P., Barrea, C., Vincent, M.-F., De Laet, C., Van Coster, R., Seneca, S., Marie, S., Nassogne, M.C., 2016. Evidence of a wide spectrum of cardiac involvement due to ACAD9 mutations: Report on nine patients. Mol. Genet. Metab. 1-5 https://doi.org/ 10.1016/j.ymgme.2016.05.005.

Fiedorczuk, K., Sazanov, L.A., 2018. Mammalian mitochondrial complex I structure and disease-causing mutations. Trends Cell Biol. 28, 835-867. https://doi.org/10.1016/ j.tcb.2018.06.006.

Formosa, L.E., Muellner-Wong, L., Reljic, B., Sharpe, A.J., Jackson, T.D., Beilharz, T.H., Stojanovski, D., Lazarou, M., Stroud, D.A., Ryan, M.T., 2020. Dissecting the roles of mitochondrial complex I intermediate assembly complex factors in the biogenesis of complex I. Cell Rep. 31, 107541 https://doi.org/10.1016/j.celrep.2020.107541.

Gerards, M., van den Bosch, B.J.C., Danhauser, K., Serre, V., van Weeghel, M., Wanders, R.J.A., Nicolaes, G.A.F., Sluiter, W., Schoonderwoerd, K., Scholte, H.R., Prokisch, H., Rötig, A., de Coo, I.F.M., Smeets, H.J.M., 2010. Riboflavin-responsive oxidative phosphorylation complex I deficiency caused by defective ACAD9: new function for an old gene. Brain 134, 210-219. https://doi.org/10.1093/brain/ awq273.

Giachin G, Jessop M, Bouverot R, Acajjaoui S, Saïdi M, Chretien A, Bacia-Verloop M, Signor L, Mas PJ, Favier A, Borel Meneroud E, Hons M, Hart DJ, Kandiah E, Boeri Erba E, Buisson A, Leonard G, Gutsche I, Soler-Lopez M., 2021. Assembly of the Mitochondrial Complex I assembly complex suggests a regulatory role for deflavination. Angew. Chem. Int. Ed. Engl. Feb 23;60(9):4689-4697. doi:10.1002/ anie. 202011548.

Gilhooley MJ, Owen N, Moosajee M, Yu Wai Man P., 2021. From transciptimics to treatment in inherited optic neuropathies. Genes (Basel). 2021 Jan 22;12(2):147. doi: 10.3390 /genes 12020147 .

Haack, T.B., Danhauser, K., Haberberger, B., Hoser, J., Strecker, V., Boehm, D., Uziel, G., Lamantea, E., Invernizzi, F., Poulton, J., Rolinski, B., Iuso, A., Biskup, S., Schmidt, T., Mewes, H.-W., Wittig, I., Meitinger, T., Zeviani, M., Prokisch, H., 2010. Exome sequencing identifies ACAD9 mutations as a cause of complex I deficiency. Nature Publishing Group 42, 1131-1134. https://doi.org/10.1038/ng.706.

Kadoya, T., Sakakibara, A., Kitayama, K., Yamada, Y., Higuchi, S., Kawakita, R., Kawasaki, Y., Fujino, M., Murakami, Y., Shimura, M., Murayama, K., Ohtake, A., Okazaki, Y., Koga, Y., Yorifuji, T., 2019. Successful treatment of infantile-onset ACAD9-related cardiomyopathy with a combination of sodium pyruvate, betablocker, and coenzyme Q10. J. Pediatr. Endocrinol. Metab. 32, 1181-1185. https:// doi.org/10.1515/jpem-2019-0205.

Koene, S., Rodenburg, R.J., van der Knaap, M.S., Willemsen, M.A.A.P., Sperl, W., Laugel, V., Ostergaard, E., Tarnopolsky, M., Martin, M.A., Nesbitt, V., Fletcher, J., Edvardson, S., Procaccio, V., Slama, A., van den Heuvel, L.P.W.J., Smeitink, J.A.M., 2012. Natural disease course and genotype-phenotype correlations in Complex I deficiency caused by nuclear gene defects: what we learned from 130 cases. J. Inherit. Metab. Dis. 35, 737-747. https://doi.org/10.1007/s10545-012-9492-z.

Lagoutte-Renosi, J., Ségalas-Milazzo, I., Crahes, M., Renosi, F., Menu-Bouaouiche, L. Torre, S., Lardennois, C., Rio, M., Marret, S., Brasse-Lagnel, C., Laquerrière, A., Bekri, S., 2015. Lethal Neonatal Progression of Fetal Cardiomegaly Associated to ACAD9 Deficiency, in: JIMD Reports, Volume 18, JIMD Reports. Springer Berlin Heidelberg, Berlin, Heidelberg, pp. 1-10. doi:10.1007/8904_2015_499.

Maresca, A., la Morgia, C., Caporali, L., Valentino, M.L., Carelli, V., 2012. The optic nerve: A "mito-window" on mitochondrial neurodegeneration. Mol. Cell. Neurosci. 1-15 https://doi.org/10.1016/j.mcn.2012.08.004.

Mosegaard, S., Dipace, G., Bross, P., Carlsen, J., Gregersen, N., Olsen, R.K.J., 2020 Riboflavin deficiency-implications for general human health and inborn errors of metabolism. Int. J. Mol. Sci. 21 https://doi.org/10.3390/ijms21113847.

Nouws, J., Brinke, te, H., Nijtmans, L.G., Houten, S.M., 2013. ACAD9, a complex I assembly factor with a moonlighting function in fatty acid oxidation deficiencies. Hum. Mol. Genet. 23, 1311-1319. doi:10.1093/hmg/ddt521.

Nouws, J., Nijtmans, L., Houten, S.M., van den Brand, M., Huynen, M., Venselaar, H., Hoefs, S., Gloerich, J., Kronick, J., Hutchin, T., Willems, P., Rodenburg, R., Wanders, R., van den Heuvel, L., Smeitink, J., Vogel, R.O., 2010. Acyl-CoA dehydrogenase 9 is required for the biogenesis of oxidative phosphorylation Complex I. Cell Metab. 12, 283-294. https://doi.org/10.1016/j.cmet.2010.08.002.

Repp, B.M., Mastantuono, E., Alston, C.L., Schiff, M., Haack, T.B., Rötig, A., Ardissone, A., Lombès, A., Catarino, C.B., Diodato, D., Schottmann, G., Poulton, J., Burlina, A., Jonckheere, A., Munnich, A., Rolinski, B., Ghezzi, D., Rokicki, D., Wellesley, D., Martinelli, D., Wenhong, D., Lamantea, E., Ostergaard, E., Pronicka, E., Pierre, G., Smeets, H.J.M., Wittig, I., Scurr, I., de Coo, I.F.M., Moroni, I., Smet, J., Mayr, J.A., Dai, L., de Meirleir, L., Schuelke, M., Zeviani, M., Morscher, R.J., McFarland, R., Seneca, S., Klopstock, T., Meitinger, T., Wieland, T., Strom, T.M., Herberg, U., Ahting, U., Sperl, W., Nassogne, M.C., Ling, H., Fang, F., Freisinger, P., Van Coster, R., Strecker, V., Taylor, R.W., Häberle, J., Vockley, J., Prokisch, H., Wortmann, S., 2018. Clinical, biochemical and genetic spectrum of 70 patients with ACAD9 deficiency: is riboflavin supplementation effective? 1-10. doi:10.1186/s13023-018 0784-8.

Schiff, M., Haberberger, B., Xia, C., Mohsen, A.-W., Goetzman, E.S., Wang, Y., Uppala, R., Zhang, Y., Karunanidhi, A., Prabhu, D., Alharbi, H., Prochownik, E.V., Haack, T., Häberle, J., Munnich, A., Rötig, A., Taylor, R.W., Nicholls, R.D., Kim, J.-J., Prokisch, H., Vockley, J., 2015. Complex I assembly function and fatty acid oxidation enzyme activity of ACAD9 both contribute to disease severity in ACAD9 deficiency. Hum. Mol. Genet. 24, 3238-3247. https://doi.org/10.1093/hmg/ddv074.

Schrank, B., Schoser, B., Klopstock, T., Schneiderat, P., Horvath, R., Abicht, A., HolinskiFeder, E., Augustis, S., 2017. Lifetime exercise intolerance with lactic acidosis as key manifestation of novel compound heterozygous ACAD9 mutations causing complex I deficiency. Neuromuscul. Disord. 1-14 https://doi.org/10.1016/j. nmd.2017.02.005. 